\title{
Fluência Tecnológico-Pedagógica na Docência Universitária
}

\author{
Technological-Pedagogical Fluency in University Teaching
}

Fluidez tecnológico-pedagógica en la enseñanza universitaria

DANIELE DA ROCHA SCHNEIDER ${ }^{a}$

ROGÉRIO TUBIAS SCHRAIBER ${ }^{b}$

ELENA MARIA MALLMANN ${ }^{c}$

\section{Resumo}

A docência na Educação Superior exige uma multiplicidade de habilidades do professor frente aos contextos emergentes que vem alterando os modelos tradicionais de ensino-aprendizagem. Nesse sentido, o artigo destaca a Fluência Tecnológico-Pedagógica como um desafio à Docência Universitária. Tem como objetivo analisar a Fluência Tecnológico-Pedagógica de professores em um curso de formação continuada, "REA: Educação para o Futuro", ofertado através de Small Open Online Course a professores e servidores da rede pública do ensino básico do estado do Rio Grande do Sul. Para tanto, resgata-se a base teórica que sustenta o conceito, problematizando seus desdobramentos nas inter-relações didáticas do trabalho do professor. A delimitação, organização e análise dos dados foi realizada a partir da orientação metodológica da pesquisa-ação por meio de três matrizes: Matriz Dialógico-Problematizadora (MDP), Matriz Temático-Organizadora (MTO) e Matriz Temático-Analítica (MTA). Os resultados apontam que o conjunto de saberes e práticas pedagógicas inerentes à docência na Educação Superior são viabilizados pelo desenvolvimento de Fluência Tecnológico-Pedagógica. O professor fluente avança para níveis de reflexão, análise e produção de conhecimento mais profundos em relação às ações de planejamento, organização

\footnotetext{
a Universidade Federal de Santa Maria (UFSM), Santa Maria, RS, Brasil. Doutora em Informática na Educação, e-mail: dani.qmc@gmail.com

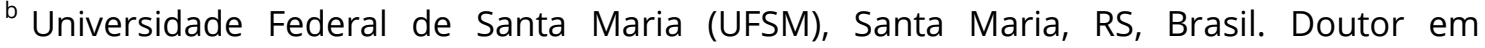
Educação, e-mail: rgartt@gmail.com

' Universidade Federal de Santa Maria (UFSM), Santa Maria, RS, Brasil. Doutora em Educação, e-mail: elena.ufsm@gmail.com
} 
de metodologias e estratégias didáticas, avaliação e interações entre os participantes. Conclui-se que maior Fluência Tecnológico-Pedagógica dos professores reverte em qualidade no processo ensino-aprendizagem.

Palavras-chave: Professor. Docência Universitária. Fluência TecnológicoPedagógica. Educação Superior.

\begin{abstract}
Teaching in university education requires a multiplicity of teacher skills in the face of emerging contexts that have been changing traditional teaching-learning models. In this sense, the article highlights Technological-Pedagogical Fluency as a challenge to university teaching. It aims to analyze the Technological-Pedagogical Fluency of teachers in a Small Open Online Course called "REA: Education for the Future" offered to teachers and public servants of public schools in the state of Rio Grande do Sul. Therefore, the theoretical basis that supports the concept is recovered. The consequences in the didactic interrelationships of the teacher's work are problematized. The delimitation, organization and analysis of the data was carried out based on the methodological orientation of the action research through three matrices: DialogicalProblematizing Matrix (MDP), Thematic-Organizing Matrix (MTO) and ThematicAnalytical Matrix (MTA). The results show that the set of knowledge and pedagogical practices inherent to teaching in university education are made possible by the development of Technological-Pedagogical Fluency. The fluent teacher advances to deeper levels of reflection, analysis and knowledge production. All this in relation to planning actions, organization of methodologies and didactic strategies, evaluation and interactions between participants. In this face, greater Technological-Pedagogical Fluency of teachers generates more quality in the teaching-learning process.
\end{abstract}

Keywords: Teacher. University Teaching. Technological-Pedagogical Fluency. Higher education.

\title{
Resumen
}

La enseñanza en la educación superior requiere una multiplicidad de habilidades docentes frente a contextos emergentes que han estado cambiando los modelos tradicionales de enseñanza-aprendizaje. En este sentido, el artículo destaca la fluidez tecnológico-pedagógica como un desafío para la enseñanza universitaria. Su objetivo es analizar la fluidez tecnológico-pedagógica de los docentes en un curso de educación continua, "REA: Educación para el futuro", que se ofrece a través de un curso en línea pequeño y abierto a docentes y servidores públicos de escuelas públicas del estado de Río Grande do Sur. Por lo tanto, la base teórica que apoya el concepto se recupera, problematizando sus consecuencias en las interrelaciones didácticas del trabajo del profesor. La delimitación, organización y análisis de los datos se realizó en base a la orientación metodológica de la investigación en acción a través de tres matrices: matriz de problemas dialógicos (MDP), matriz de organización temática (MTO) y matriz de 
análisis temático (MTA). Los resultados muestran que el conjunto de conocimientos y prácticas pedagógicas inherentes a la enseñanza en la educación superior son posibles gracias al desarrollo de la fluidez tecnológico-pedagógica. El maestro fluido avanza a niveles más profundos de reflexión, análisis y producción de conocimiento en relación con las acciones de planificación, organización de metodologías y estrategias didácticas, evaluación e interacciones entre los participantes. Se concluye que una mayor fluidez tecnológico-pedagógica de los docentes revierte a la calidad en el proceso de enseñanza-aprendizaje.

Palabras clave: Profesor. Docencia universitaria. Fluidez Tecnológico-Pedagógica. Educación universitaria.

\section{Introdução}

Tema de muitos estudos, a Docência Universitária é frequentemente debatida por seus pesquisadores, sendo muitos destes docentes do Ensino Superior. Como um processo complexo a ser construído ao longo do desenvolvimento profissional, a docência requer conhecimentos específicos condizentes com as inovações tecnológicas emergentes.

A inserção das tecnologias nas metodologias de ensino-aprendizagem e na organização do trabalho pedagógico tem inferências diretas no processo de ensinar e aprender. Requer do professor universitário o desenvolvimento de Fluência Tecnológico-Pedagógica (FTP) para implementar ensino, pesquisa e extensão.

A FTP viabiliza saberes e práticas, pois o conhecimento sobre a tecnologia, a didática, a epistemologia e a pedagogia requer ações planejadas e sistematizadas. $\mathrm{O}$ professor realiza uma série de atribuições para as quais o conhecimento acerca da tecnologia e do modo como integrá-la ao pedagógico são necessidades constantes quando se pensa nos recursos tecnológicos como potencializadores do processo ensino-aprendizagem.

Ao desenvolver e aprimorar a FTP o professor tem maiores condições de implementar ações relativas à docência como planejamento, organização de metodologias e estratégias didáticas, avaliação e interações entre os participantes. Esses elementos constitutivos da ação docente requerem níveis de reflexão, análise e produção de conhecimento condizentes com as demandas impostas pela cultura contemporânea. 
Para compreender esse conceito, que se constitui desafio à Docência Universitária, realiza-se revisão bibliográfica da base teórica e problematiza-se os seus desdobramentos nas inter-relações didáticas da prática pedagógica do docente universitário. Desta forma, o artigo divide-se em cinco seções, sendo a primeira esta introdução. Na segunda, apresenta-se a base teórica em torno do conceito de FTP e sua relação com a Docência Universitária. Na terceira, a metodologia aplicada e em seguida os resultados e, por fim, as considerações finais.

\section{Fluência Tecnológico-Pedagógica: implicações para a prática docente universitária}

Diferentes termologias relacionadas ao termo fluência são encontradas na literatura. Fluência tecnológica (PAPERT e RESNICK, 1995; DEMO, 2008), Fluência com tecnologias (KAFAI et al., 1999), Alfabetização Digital (TAKAHASHI, 2000), Alfabetização Midiática e Informacional (WILSON, C. et al., 2013), Competência em TIC (UNESCO, 2009), Competência (BEHAR, 2013), Fluência Tecnológico-Pedagógica (MALLMANN, SCHNEIDER, MAZZARDO, 2013), Fluência digital (EDUCAUSE HORIZON REPORT, 2019).

Para Papert e Resnick (1995), a "fluência tecnológica envolve a capacidade de expressar, explorar e realizar ideias com as novas mídias tecnológicas - e aproveitar essas mídias para aprimorar o aprendizado em outros domínios (PAPERT; RESNICK, 1995, s/p, tradução dos autores). De modo semelhante, Mit Media Lab (2015, s/p) defende que "ser tecnologicamente fluente implica não apenas ser capaz de utilizar as ferramentas tecnológicas, mas também saber como construir coisas com significado com essas ferramentas".

Isso significa que a fluência tecnológica se acrescenta ao conhecimento pedagógico, potencializando e inovando o ensino-aprendizagem (SCHRAIBER; MALLMANN, 2018). No mesmo sentido, para Schlemmer (2011, s/p) a "fluência tanto tecnológica digital, quanto pedagógica (no caso dos docentes), [...] estão totalmente imbricadas e se materializa por meio do desenvolvimento das práticas pedagógicas".

De acordo com Amaral e Amiel (2013), 
Atingir um alto nível de fluência tecnológica permite um nível de conforto com o momento tecnológico atual e a habilidade de confrontar novos desenvolvimentos com certa desenvoltura. [...] Um nível de fluência é necessário para que se entenda o momento histórico, se faça uso produtivo de ferramentas e seja crítico quanto a suas práticas (AMARAL; AMIEL, 2013, p. 03)

Por outro lado "não basta dar um computador ao professor e esperar fluência, nem transposição didática, da mesma maneira que o uso contínuo de novas mídias pelos alunos em nada garante um alto nível de fluência” (AMARAL; AMIEL, 2013, p. 04). Para os autores, adquirir fluência tecnológica envolve habilidade em confrontar desenvolvimentos novos com desenvoltura, também, em resposta parcial aos anseios de uma "alfabetização" que está em fluxo constante e mediada pelo desenvolvimento tecnológico.

O documento Educause Horizon Report (2019, p. 14, tradução nossa) trata da fluência tecnológica como fluência digital, a qual "é a capacidade de alavancar ferramentas digitais e plataformas para se comunicar criticamente, projetar criativamente, tomar decisões informadas, resolver antecipadamente novo problema".

Para Kafai et al. (1999, p. 6-7, tradução nossa) "Ser fluente é pessoal no sentido de que os indivíduos fluentes com tecnologias da informação avaliam, distinguem, aprendem e usam novas tecnologias da informação conforme apropriado para suas atividades pessoais e profissionais". Desse modo, a fluência tecnológica corresponde "a capacidade de reformular conhecimentos, expressar-se criativamente e de forma adequada, para produzir e gerar informação (em vez de simplesmente compreendê-la)" (KAFAI, et al., 1999, p. 9, tradução nossa). "Implica uma progressão em relação ao que se associa ao conceito de alfabetização digital" a qual reduz a ação do sujeito a apenas consumidor da informação (TAROUCO, 2013, p. 287).

Nos estudos de Kafai et al. (1999) “adquirir fluência com as tecnologias educacionais é desenvolver habilidades contemporâneas, capacidades intelectuais e conceitos fundamentais". Diante disso, a FTP está alicerçada na tríade composta por esses três eixos, sendo: as Habilidades Contemporâneas as que correspondem à capacidade de usar programas com aplicação imediata, envolvendo a prática no desenvolvimento de habilidades para criar com as ferramentas tecnológicas, sendo mais do que apenas o conhecimento teórico sobre as mesmas; os Conceitos Fundamentais os que envolvem a explicação do como e do porquê da tecnologia, 
além de dicas de suas oportunidades e limitações, fazendo referência ao conhecimento teórico e abrangente que se sabe sobre tecnologia e ferramentas tecnológicas; as Capacidades Intelectuais, que correspondem à capacidade tanto de aplicação da tecnologia em situações complexas como à de instruir os estudantes a usarem a mídia em proveito próprio, estando relacionadas à reflexão e solução de problemas baseadas na tecnologia.

Dito isso, desenvolver as habilidades contemporâneas, conhecer os conceitos fundamentais e ampliar capacidades intelectuais são ações que efetivam o compartilhamento de informações, a colaboração livre e aberta em rede, a utilização das máquinas e da sua adaptação. Esses três eixos constituintes da FTP, cujo aprimoramento qualifica a prática do professor universitário, amplia a integração das tecnologias educacionais em rede e potencializa o processo ensino-aprendizagem (MALLMANN; JACQUES, 2017).

Mallmann, Mazzardo e Schneider (2013), definem a FTP como

a capacidade de mediar o processo de ensino-aprendizagem com conhecimentos sobre planejamento, estratégias metodológicas, conteúdos, material didático, tecnologias educacionais em rede com destaque para os AVEA, realização de ações com os alunos para desafiar, dialogar, problematizar, instigar a reflexão e a criticidade, incentivar a interação com o grupo e interatividade com ambiente e materiais didáticos, o desenvolvimento de trabalhos colaborativos, a autonomia, autoria e coautoria, a emancipação, monitorar o estudo e realização das atividades dos alunos identificando dificuldades e propondo soluções, manter boa comunicação no ambiente virtual com todos os envolvidos, reflexão sobre as potencialidades didáticas dos recursos utilizados, práticas didáticas implementadas e sobre a própria atuação na tutoria (MALLMANN, SCHNEIDER, MAZZARDO, 2013, p. 5, grifo das autoras)

O acoplamento da fluência tecnológica à pedagógica, que resulta no conceito de FTP, parte do princípio de que as práticas pedagógicas precisam ser pensadas e implementadas levando em consideração conhecimentos conceituais e práticas, teoria e ações. Nesse sentido, Toebe et al. (2018), destaca que a FTP

não se restringe ao saber-fazer técnico, mas está consoante ao disposto nos fundamentos epistemológicos, na organização curricular de um curso, nos aspectos sociais, éticos, políticos e ontológicos dos envolvidos nos processos, nas condições operativas e logísticas permitidas pela infraestrutura do contexto (TOEBE et al., 2018, p. 1140).

A FTP, ao aliar questões didáticas metodológicas e tecnológicas, a partir de conhecimentos, ações e reflexões do processo ensino-aprendizagem, viabiliza a 
produção de conhecimento, gerando inovações curriculares. Nessa perspectiva da inovação Veiga (2006, p. 3) aponta que uma das características da Docência Universitária está ligada justamente à inovação quando: a) rompe com a forma conservadora de ensinar, aprender, pesquisar e avaliar; b) reconfigura saberes, procurando superar as dicotomias entre conhecimento científico e senso comum, ciência e cultura, educação e trabalho, teoria e prática, etc.; c) explora novas alternativas teórico-metodológicas em busca de outras possibilidades de escolhas; d) procura a renovação da sensibilidade ao alicerçar-se na dimensão estética, no novo, no criativo, na inventividade; e) ganha significado quando é exercida com ética.

Sendo um processo de aprendizagem permanente que se desenvolve e se aprimora ao longo da vida, a FTP se caracteriza em "saber fazer o melhor em cada situação, com cada recurso, sendo que não acontece no improviso, é resultado de formação" (MALLMANN; SCHNEIDER; MAZZARDO, 2013, p. 4). Isso envolve, hoje, um dos desafios da Docência Universitária: saber mediar conhecimentos específicos com os pedagógicos e tecnológicos nas inter-relações didáticas.

O professor universitário que desenvolve FTP tem condições de reconfigurar saberes, implementar novas metodologias de ensino-aprendizagem, buscar o novo, sendo criativo, e criar significado com a tecnologia na sua prática pedagógica. É importante salientar que isso tudo contribui para a solidificação e fundamentação dessa prática, pois como argumenta Veiga (2006, p. 6) "A prática pedagógica profissional exige uma fundamentação teórica explícita”.

Essa fundamentação teórica destacada por Veiga (2006) é basilar na FTP. Representa um conjunto de saberes epistemológicos, didáticos e tecnológicos. Esses saberes se interconectam e se complementam e estão atrelados aos conhecimentos que o professor deve ter acerca da pedagogia, da psicologia, da política, da filosofia da mediação pedagógica, da avaliação assim como dos recursos e interfaces das tecnologias em rede.

Em um contexto onde a educação e a tecnologia se interconectam, o professor com FTP tem capacidade de adaptar metodologias de ensino, exercitando suas possibilidades didático-pedagógicas, visto que a simples incorporação de tecnologias não pressupõe práticas inovadoras. O que torna o processo ensino- 
aprendizagem emancipatório é a proposta epistemológica-didático-pedagógica que suporta o uso de determinada tecnologia (SCHLEMMER; BACKES, 2008).

De acordo com Soares e Cunha (2010, p. 579) as tecnologias na sociedade atual significam uma:

[...] revolução dos meios de comunicação e informação, que, ao possibilitar o acesso aos conhecimentos de forma ágil e dinâmica, põe em xeque o papel de porta-voz inquestionável do saber assumido historicamente pelo professor universitário por meio dos métodos tradicionais de ensino.

Assim sendo, as tecnologias têm o poder de transformar a prática pedagógica, mas essa transformação depende da FTP que esse professor desenvolver. É a FTP que viabiliza a transformação dos métodos tradicionais de ensino em metodologias inovadoras a partir de recursos tecnológicos.

Concorda com tal questão Bolzan (2009, p. 145) ao afirmar que "[...] à medida que são utilizados processos e estratégias mobilizadores de reflexão docente sobre a própria prática, possibilita-se que esses sujeitos se tornem capazes de aprender por meio de suas experiências e de gerar novos conhecimentos pedagógicos". Ademais, o estudante se torna mais participativo, dividindo a responsabilidade do ensino-aprendizagem, como vemos nas palavras de Anastasiou (2009, p. 185) ao questionar “[...] qual a melhor forma de ensinar o conteúdo? Essa questão coloca no professor toda a responsabilidade, desconsiderando que este depende, para sua efetivação, da inserção participativa do aluno, pela efetivação da aprendizagem". Os recursos tecnológicos podem ser uma alternativa para essa parceria entre professor e estudante.

Desse modo, surge uma nova metodologia a partir da tecnologia, esta que trata, nas palavras de Georgen (2006, p. 80), “[...] não de desenvolvimento modernizador, mas de desenvolvimento autêntico, não de tecnologia avançada, mas de tecnologia apropriada”. É quando professor revê seu conceito de ensinoaprendizagem e começa a construir seus conhecimentos para aquilo que Cunha (2005) chama de docência emancipatória. A FTP subsidia essa emancipação na medida em que amplia clareza epistemológica e conhecimentos didáticometodológicos do processo ensino-aprendizagem na Educação Superior.

Nesse sentido, embasados no levantamento teórico que define e caracteriza a FTP, apresenta-se a seguir a metodologia que norteou a pesquisa. 


\section{Metodologia}

Esta pesquisa-ação foi realizada em um programa de formação continuada de professores da Educação Básica no Rio Grande do Sul. O curso REA: Educação para o Futuro $^{\mathrm{a}}$, desenvolvido no formato Small Open Online Course (SOOC), teve como tema central os Recursos Educacionais Abertos (REA).

A tipologia de pesquisa delimitada possibilita estudo com os sujeitos da prática, tornando-a de caráter democrático cuja intencionalidade está voltada à promoção de mudanças sociais. Kemmis e Mctaggart (1988), destacam essa estratégia como participativa, política, permitindo aos sujeitos envolvidos a criação de argumentações examinadas da prática. Para Elliot (1997), a pesquisa-ação produz conhecimentos sobre os problemas reais, com vista a atingir uma melhora da situação individual e coletiva.

A investigação, nesse sentido, tornou-se autorreflexiva, realizada por docentes sobre sua atuação no curso de formação continuada sobre REA. Ao ocupar-se "do melhoramento das práticas, dos entendimentos e das situações de caráter educativo, baseia-se necessariamente num enfoque da verdade e da ação como socialmente construída e incorporada pela história" (CARR \& KEMMIS, 1988, p. 193). Ainda segundo os autores, é preciso que os próprios docentes construam a teoria educativa por meio da reflexão crítica sobre sua prática pedagógica. Isso requer três condições.

A primeira, que um projeto tenha planejado como tema uma prática social, considerada como uma forma de ação estratégica susceptível de melhoramento; a segunda, que dito projeto percorra uma espiral planejamento, ação, observação e reflexão, estando todas estas características implantadas e inter-relacionadas sistemática e autocriticamente; a terceira, que o projeto implique aos responsáveis das práticas em todos e cada um dos momentos da atividade, ampliando gradualmente a participação no projeto para incluir a outros afetados pelas práticas, e mantendo um controle colaborativo do processo (CARR; KEMMIS, 1988, p. 177).

\footnotetext{
${ }^{a}$ Cf. https://gepeter.proj.ufsm.br/repositorio/items/show/5.
} 
No plano da espiral autorreflexiva (Figura 1), implementou-se planejamento, ação, observação e reflexão em duas edições do curso, problematizando momentos retrospectivos e ações prospectivas necessárias para melhoria gradativa da FTP, foco desse estudo.

Figura 1 - Estratégias e etapas da pesquisa-ação

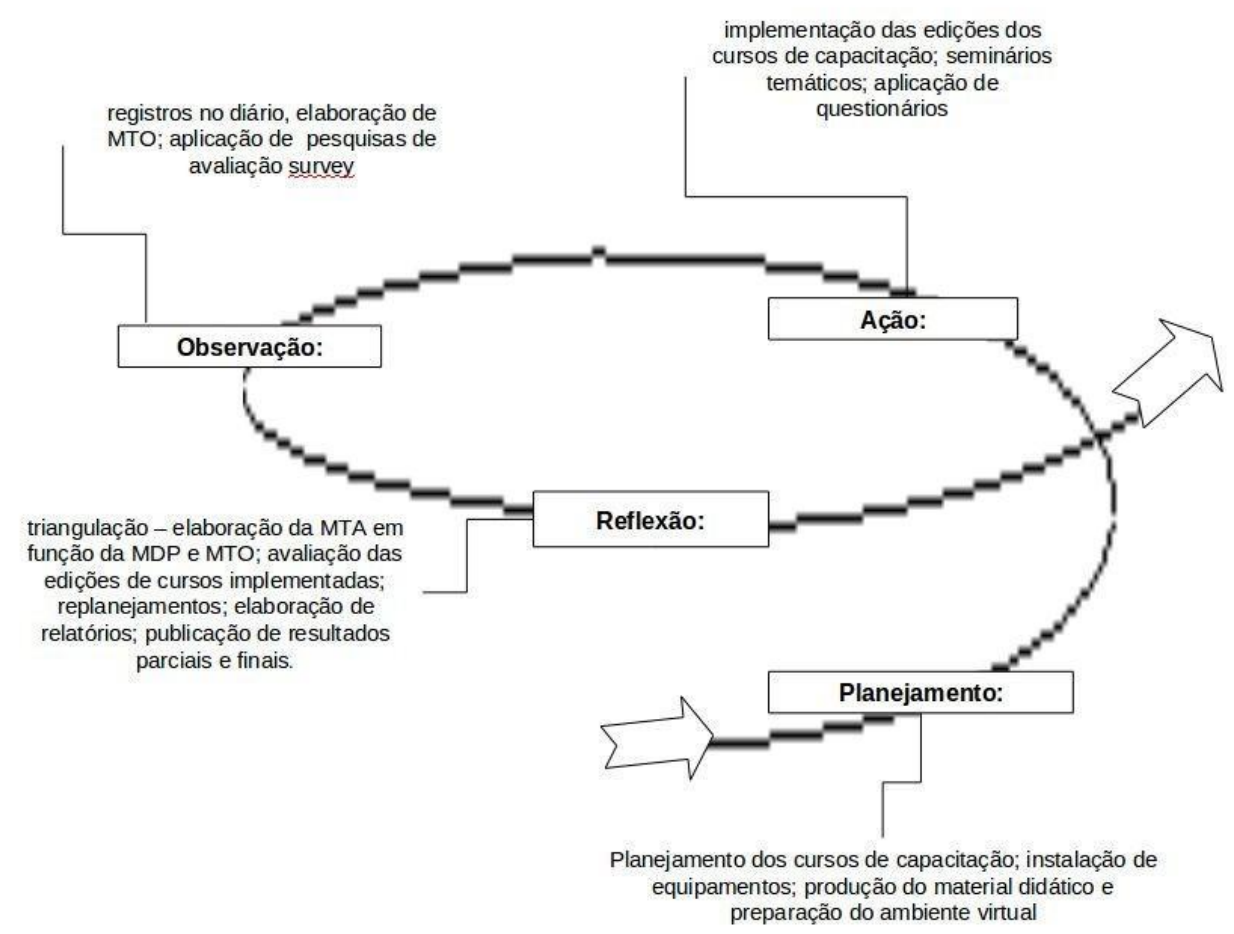

Fonte: Elaborado pelos autores (2019).

Para organizar processualmente as evidências nas etapas metodológicas de uma pesquisa-ação (delimitação da temática, produção e análise de dados e conclusões) utilizou-se o procedimento teórico-metodológico chamado matrizes cartográficas denominadas: Matriz Dialógico-Problematizadora — MDP; Matriz Temático-Organizadora - MTO; e Matriz Temático-Analítica — MTA (MALLMANN, 2008).

A MDP (Quadro 1), desenvolvida com origens na Tábua de Invenção Aristotélica (KEMMIS; MCTAGGART, 1988, p. 123) sistematiza a preocupação temática, favorecendo o direcionamento, a organização, a delimitação e a discussão dialógica em torno dos componentes fundamentais de um processo educacional. 
Quadro 1 - Matriz Dialógico-Problematizadora

\begin{tabular}{|c|c|c|c|c|}
\hline \multicolumn{5}{|c|}{ Professores: Professores e servidores da rede pública do ensino básico do estado do Rio Grande do Sul } \\
\hline \multicolumn{5}{|c|}{ Estudantes: Estudantes da Educação Básica das escolas envolvidas } \\
\hline \multicolumn{5}{|c|}{$\begin{array}{l}\text { Tema: Inovação didático-metodológica mediada por tecnologias educacionais hipermídia, } \\
\text { especialmente Recursos Educacionais Abertos }\end{array}$} \\
\hline \multicolumn{5}{|c|}{$\begin{array}{l}\text { Contexto: Diretrizes das políticas públicas educacionais para integração de tecnologias na } \\
\text { educação básica }\end{array}$} \\
\hline & Professores 1 & Estudantes 2 & Temática 3 & Contexto 4 \\
\hline 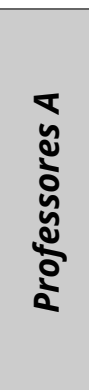 & $\begin{array}{l}\text { A1) Professores } \\
\text { colaboram para } \\
\text { introduzir, aprofundar e } \\
\text { consolidar a integração } \\
\text { de tecnologias } \\
\text { educacionais } \\
\text { hipermidiáticas, } \\
\text { especialmente REA, na } \\
\text { EB? }\end{array}$ & $\begin{array}{l}\text { A2) Os professores } \\
\text { desafiam os estudantes } \\
\text { a realizarem atividades } \\
\text { de estudo } \\
\text { envolvendo/utilizando } \\
\text { tecnologias educacionais } \\
\text { hipermidiáticas, } \\
\text { especialmente REA, na } \\
\text { EB? }\end{array}$ & $\begin{array}{l}\text { A3) Os professores } \\
\text { mesclam materiais } \\
\text { didáticos impressos e } \\
\text { tecnologias } \\
\text { educacionais } \\
\text { hipermidiáticas, } \\
\text { especialmente REA, na } \\
\text { EB? }\end{array}$ & $\begin{array}{l}\text { A4) Os professores } \\
\text { contextualizam os } \\
\text { conteúdos curriculares } \\
\text { por meio da integração } \\
\text { de tecnologias } \\
\text { educacionais } \\
\text { hipermidiáticas, } \\
\text { especialmente REA, na } \\
\text { EB? }\end{array}$ \\
\hline 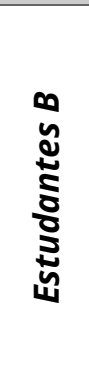 & $\begin{array}{l}\text { B1) Os estudantes atuam } \\
\text { colaborativamente com } \\
\text { os professores mediados } \\
\text { por tecnologias } \\
\text { educacionais hipermídia? }\end{array}$ & $\begin{array}{l}\text { B2) Os estudantes } \\
\text { colaboram entre si em } \\
\text { torno de atividades de } \\
\text { estudo mediadas por } \\
\text { tecnologias educacionais } \\
\text { hipermídia, } \\
\text { especialmente REA, na } \\
\text { EB? }\end{array}$ & $\begin{array}{l}\text { B3) Os estudantes } \\
\text { produzem } \\
\text { colaborativamente a } \\
\text { aprendizagem mediados } \\
\text { por tecnologias } \\
\text { educacionais hipermídia, } \\
\text { especialmente REA, na } \\
\text { EB? }\end{array}$ & $\begin{array}{l}\text { B4) Os estudantes } \\
\text { contextualizam suas } \\
\text { situações-limite diante } \\
\text { dos Recursos e } \\
\text { Atividades } \\
\text { programados } \\
\text { hipermidiaticamente } \\
\text { pelos professores na } \\
\text { EB? }\end{array}$ \\
\hline 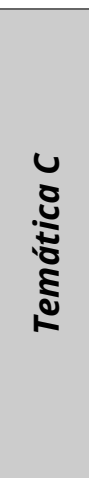 & $\begin{array}{l}\text { C1) A inovação didático- } \\
\text { metodológica mediada } \\
\text { por tecnologias } \\
\text { educacionais hipermídia, } \\
\text { especialmente Recursos } \\
\text { Educacionais Abertos } \\
\text { (REA), é considerada um } \\
\text { desafio na prática } \\
\text { pedagógica na EB? }\end{array}$ & $\begin{array}{l}\text { C2) O potencial da } \\
\text { integração de } \\
\text { tecnologias educacionais } \\
\text { hipermídia, } \\
\text { especialmente Recursos } \\
\text { Educacionais Abertos } \\
\text { (REA), é compreendido } \\
\text { pelos estudantes da EB? }\end{array}$ & $\begin{array}{l}\text { C3) A inovação didático- } \\
\text { metodológica mediada } \\
\text { por tecnologias } \\
\text { educacionais hipermídia, } \\
\text { especialmente Recursos } \\
\text { Educacionais Abertos } \\
\text { (REA), pode melhorar a } \\
\text { qualidade do ensino- } \\
\text { aprendizagem na EB? }\end{array}$ & $\begin{array}{l}\text { C4) A inovação didático- } \\
\text { metodológica na EB é } \\
\text { parametrizada pelas } \\
\text { tecnologias } \\
\text { educacionais } \\
\text { hipermídia, } \\
\text { especialmente } \\
\text { Recursos Educacionais } \\
\text { Abertos (REA), } \\
\text { disponíveis nos portais } \\
\text { públicos? }\end{array}$ \\
\hline 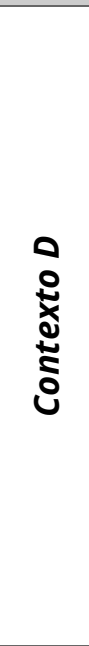 & $\begin{array}{l}\text { D1) As políticas públicas } \\
\text { para educação básica } \\
\text { estabelecem diretrizes } \\
\text { claras para que os } \\
\text { professores possam } \\
\text { planejar, produzir, } \\
\text { reutilizar e recompartilhar } \\
\text { recursos que permitam } \\
\text { aprofundar e consolidar } \\
\text { conhecimentos por meio } \\
\text { da integração das } \\
\text { tecnologias educacionais } \\
\text { hipermídia, especialmente } \\
\text { os Recursos Educacionais } \\
\text { Abertos (REA)? }\end{array}$ & $\begin{array}{l}\text { D2) As políticas públicas } \\
\text { para educação básica } \\
\text { estabelecem diretrizes } \\
\text { claras para que os } \\
\text { estudantes possam } \\
\text { aprofundar e consolidar } \\
\text { conhecimentos por } \\
\text { meio da integração das } \\
\text { tecnologias } \\
\text { educacionais } \\
\text { hipermídia, } \\
\text { especialmente os } \\
\text { Recursos Educacionais } \\
\text { Abertos (REA)? }\end{array}$ & $\begin{array}{l}\text { D3) A implementação } \\
\text { de cursos de formação } \\
\text { continuada para } \\
\text { professores no formato } \\
\text { Small Open Online } \\
\text { Courses (SOOC) } \\
\text { potencializa inovação } \\
\text { didático-metodológica e } \\
\text { curricular na EB? }\end{array}$ & $\begin{array}{l}\text { D4) As políticas } \\
\text { públicas educacionais } \\
\text { vigentes estabelecem } \\
\text { diretrizes claras para } \\
\text { introduzir, aprofundar } \\
\text { e consolidar a } \\
\text { integração das } \\
\text { tecnologias } \\
\text { educacionais } \\
\text { hipermídia, } \\
\text { especialmente os } \\
\text { Recursos Educacionais } \\
\text { Abertos (REA) na EB? }\end{array}$ \\
\hline
\end{tabular}

Fonte: Elaborado pelos autores (2019). 
Desdobrada em 16 questões, a MDP, inicia o movimento prospectivo e retrospectivo da pesquisa-ação. Para responder às questões delimitadas, utilizou-se como instrumentos de coleta de dados observação participante, questionários tipo survey e análise de documentos, nas edições implementadas no segundo semestre de 2018 e primeiro semestre de 2019. As informações provenientes desses instrumentos foram organizadas na Matriz Temático-Organizadora (MTO) (MALLMANN, 2008), a qual organiza as informações pertinentes relacionadas à temática e a cada uma das questões formuladas na MDP.

A partir dos dados selecionados e registrados na MTO, realizou-se análise interpretativa-crítica com vistas a responder aos questionamento da MDP. Esse cruzamento das informações com os constructos do referencial teórico gerou proposições conceituais e afirmações conclusivas que foram registradas na Matriz Temático-Analítica (MTA). A MTA apresenta respostas às questões delimitadas na MDP e responde aos objetivos da pesquisa-ação.

\section{Resultado e Discussão}

Os dados da pesquisa-ação, coletados a partir da observação participante e questionário, são analisados a partir da categoria FTP. No decorrer do texto sinalizase as células de acordo com as questões da MDP, desde a pergunta [1A] até a pergunta [4D]. Como o projeto ainda está em andamento, os resultados são apontamentos de algumas questões da MDP, o que nos permite, nesse momento, jogar luz sobre a FTP na Docência Universitária.

O SOOC "REA: Educação para o futuro" envolveu nas duas edições (2018 e 2019) 15 professores e 745 cursistas com inscrições efetivadas. Com uma carga horária de 40h, objetivou introduzir e aprofundar a integração de tecnologias educacionais hipermídia, especialmente REA na Educação Básica no RS.

Implementar um curso, com uma temática contemporânea requer do professor conhecimentos sobre recursos, conteúdos e aspectos pedagógicos relacionados aos REA. Nesse sentido, os professores foram desafiados a realizarem o curso para adquirirem e aprimorarem FTP [C1]. Essa ação mobilizou interação e produção colaborativa (autoria e coautoria) entre os professores, ampliando conhecimentos e práticas relacionadas aos REA. 
Da mesma forma, a criação de um fórum de dúvidas entre os professores, no ambiente do curso, promoveu a construção colaborativa do conhecimento e da formação profissional [A1].

A FTP foi aprimorada no momento que o professor necessitou adaptar conhecimentos a uma realidade específica. Da mesma forma seu olhar retrospectivo e prospectivo em relação a estrutura do curso, interação com os curistas e dificuldades explicitadas resultou em registro e (re)planejamento, qualificando assim sua ação pedagógica [A1].

Momentos de intervenção, seja para discussão dos conteúdos, reorganização de atividades de ensino ou atualização de material didático representam envolvimento e comprometimento com o processo ensino-aprendizagem e requerem FTP [A4]. Essas ações estão relacionadas à capacidade de reformular conhecimentos e expressar-se criativamente (KAFAI et al.,1999).

Ao utilizar o computador para acessar, enviar mensagens aos cursistas, revisar o material didático, o funcionamento dos links e a interatividade com os diversos recursos que o Moodle disponibiliza, o professor demonstra conhecimento operacionais relacionados às habilidades contemporâneas. Um exemplo dessa FTP pode ser visualizado no seguinte questionamento de uma cursista: "Hoje ao acessar as respostas dos colegas para interagir, olhei novamente a minha e vi que os endereços dos REA que indiquei não ficou como link (azulzinho). Poderia me orientar como postar corretamente?”.

O professor $\mathrm{Y}$ responde a dúvida através da linguagem teórica e visual (Figura 2). Isso demonstra que o mesmo possui conhecimentos de como o aluno aprende através da disponibilização de recurso diversos [C3].

Figura 2 - Exemplo de resposta

Para ficar lincado, deve selecionar o endereço e depois clicar nessa correntinha, conforme indicado na foto.

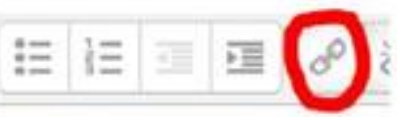

https://wmw.ufsm.br/

Depois informe o endereço no campo que solicita e clique em inserir.

Veja se consegue.

Fonte: Curso REA: Educação para o futuro (2019). 
As capacidades intelectuais se materializaram na ação docente de produção de vídeos, podcasts e redes conceituais. Essas diferentes estratégias didáticometodológicas, viabilizadas pela FTP, refletiram de modo positivo no processo ensino-aprendizagem conforme depoimento do cursista:

\begin{abstract}
Estava estudando a unidade II - Direitos autorias e Licenças abertas. Mais precisamente os vídeos: Tipos de licenças Creative Commons e Pesquisar a identificação REA na internet - apresentado pela professora X, e gostaria de colocar que os vídeos foram importantes para esclarecer as licenças de uso dos materiais na rede. [...] Muito bom e didáticos os vídeos apresentados (Cursista B).
\end{abstract}

A (co)autoria na (re)criação de materiais didáticos no formato REA resulta do movimento de ação-refleção-ação. Ao apropriar-se das tecnologias, o professor tem condições de aplicá-las em situações mais complexas.

Os conceitos fundamentais envolvem a compreensão de quando e como utilizar determinada tecnologia. Como exemplo, destaca-se o questionamento de uma cursista em uma atividade fórum: "Gostei da WebQuest, mas como faço para salvar o arquivo original?” e a professora X responde:

\begin{abstract}
A webquest foi elaborada em HTML. HTML é uma das linguagens que utilizamos para desenvolver websites. Ele não permite baixar. Uma sugestão é usar/adaptar/remixar essa webquest em outro formato. Por exemplo, pode ser feita usando um programa de apresentação de slides (sugestão: libreoffice impress, por ser um programa livre, já que estamos falando em remixar recursos educacionais abertos -) ou um programa para criar textos - doc, (LibreOffice Writer que também é livre). O programa de texto, permite produzir documentos de texto contendo figuras, tabelas ou gráficos (Professora X).
\end{abstract}

Nesse caso, a professora ao orientar a resolução do problema, oferecendo sugestões de softwares que podem ser usados em substituição para adaptação de REA, demonstra conhecimentos em relação aos conceitos fundamentais [A2]. Nessa mesma perspectiva, a FTP viabiliza ações de mediação que abrangem interação e problematização dos fóruns, orientação para o desenvolvimento das atividades, resposta às dúvidas dos cursistas, conhecimento da bibliografia, identificação de problemas e dificuldades.

Ao selecionar recursos e estratégias metodológicas adequadas ao contexto e perfil dos cursistas, o professor com FTP cria as condições para a implementação de práticas pedagógicas que contribuam para a inovação científico-tecnológica [C2]. 
Essa efetiva contribuição ficou visível a partir das respostas ao seguinte questionamento realizado através de questionário ao final da edição do curso: a implementação de cursos de formação continuada para professores no formato SOOC potencializa a inovação didático-metodológica?

Os dados indicam que 65\% dos cursistas consideram que SOOC sempre potencializa a inovação didático-metodológica; $21 \%$ que frequentemente potencializa; $12 \%$ às vezes; $2 \%$ raramente e $0 \%$ nunca. Esses dados são bastante satisfatórios, visto que a maioria dos cursistas acredita no SOOC como uma alternativa de inovação didático-metodológica, no que se insere o desenvolvimento da FTP, pois a inovação a partir dos REA solicita dos professores conhecimento tecnológico aliado ao pedagógico para a produção de recursos específicos nas diversas áreas de conhecimento.

A satisfação em relação à realização do curso por parte dos cursistas, assim como evidências relacionadas a avanços no processo ensino-aprendizagem, compreensão dos REA e aplicação nas práticas pedagógicas ficam explícitas mas mensagens abaixo.

Obrigada por ter respondido. Estou gostando muito do curso, mas tenho algumas dificuldades e pouco tempo para estudar mais sobre o assunto. Mesmo assim, este curso tem me ajudado muito nas atividades diárias em sala de aula, visando uma melhor aprendizagem [Cursista C]. [C3]

A dificuldade maior no meu ponto de vista que não tive preparação para utilizar os recursos tecnológicos, muita coisa aprendi com a necessidade, o que pode ser copiado e reutilizado era feito sem saber das devidas licenças e permissões para utilizar os diferentes recursos. Com este curso estou descobrindo novos conceitos sobre os sites que utilizamos, repertorio, REas, etc, para mim é tudo novidade e tenho que estudar e pesquisar para conseguir diferenciar (Cursista D).

Obrigado pelas informações sobre a licença no Youtube. Não tinha conhecimento da opção de selecionar a licença licença Creative Commons ao inerir os vídeos. No segundo e terceiro vídeos editei a postagem e alterei a licença, já que fui eu que criei e não possuem música, ao contrário do primeiro (Cursista E).

Essa satisfação dos cursistas está diretamente relacionada à ação pedagógica docente. O professor fluente avança para níveis de reflexão, análise e produção de conhecimento mais profundos em relação aos múltiplos contextos que envolvem a ação pedagógica. No caso específico do SOOC “REA: Educação para o futuro” o conjunto de saberes e práticas pedagógicas inerentes à docência na Educação Superior foram viabilizados pelo desenvolvimento de FTP. 


\section{Considerações finais}

Analisou-se a FTP de professores no SOOC, "REA: Educação para o Futuro". A partir do levantamento teórico, identificou-se os desdobramentos da FTP nas interrelações didáticas do trabalho do professor com base nas questões da MDP.

Considerando que a pesquisa se encontra em andamento, podemos inferir alguns resultados parciais a partir da atuação dos docentes no curso: a) oportunizou a melhoria da FTP dos professores; b) ampliou conhecimentos sobre REA; c) viabilizou compartilhamento de $\mathrm{REA}^{\mathrm{b}}$; d) oportunizou (co)autoria; e) instigou práticas colaborativas; f) gerou satisfação dos professores com sua prática pedagógica.

Os professores colaboram para introduzir, aprofundar, contextualizar e consolidar a integração de tecnologias educacionais hipermidiáticas, especialmente REA. Da mesma forma, a inovação didático-metodológica, mediada por tecnologias educacionais hipermídia, melhora a qualidade do processo ensino-aprendizagem. $\mathrm{Na}$ medida que o professor amplia sua FTP consegue tomar decisões apuradas em relação aos recursos e estratégias metodológicas, estas que tem a capacidade de levar ao desenvolvimento do conhecimento.

Nesse sentido, o uso fluente das tecnologias educacionais hipermídia, especialmente REA, se constituiu um desafio contemporâneo de inovação didáticometodológica. Portanto, maior Fluência Tecnológico-Pedagógica dos professores reverte em qualidade no processo ensino-aprendizagem.

\section{Referências}

AMARAL, S. F.; AMIEL, Tel. Nativos e Imigrantes: questionando o conceito de fluência tecnológica docente. Revista Brasileira de Informática na Educação, v. 21, n. 3, 2013. Disponível em: https://www.br-ie.org/pub/index.php/rbie/article/view/1661. Acesso em: 21 nov. 2015.

ANASTASIOU, L. G. C. Desafios atuais da teoria e prática na docência universitária. In: ISAIA, S. M. de A.; BOLZAN, D. P. V.; MACIEL, A. M. R. (orgs). Pedagogia Universitária: tecendo redes sobre a educação superior. Santa Maria: Ed. da UFSM, 2009. p. 179-192.

\footnotetext{
${ }^{\mathrm{b}}$ Exemplos de REA desenvolvidos e compartilhados pelos cursistas: -https://www.flickr.com/photos/85821577@N04/48031196638/in/dateposted-public/ -https://sites.google.com/view/reamatemtica/tarefas-9\%C2\%BA-ano -https://gepeter.proj.ufsm.br/repositorio/items/show/32 -https://www.slideshare.net/elvandirguimaraes/feelings-rea/elvandirguimaraes/feelings-rea
} 
BOLZAN, D. P. V. Formação permanente e conhecimento pedagógico compartilhado: possibilidades na docência universitária. In: ISAIA, S. M. de A.; BOLZAN, D. P. V.; MACIEL, A. M. R. (orgs). Pedagogia Universitária: tecendo redes sobre a educação superior. Santa Maria: Ed. da UFSM, 2009. p. 131-147.

BRASIL, Ministério da Educação, Secretaria da Educação Média e Tecnológica. Parâmetros Curriculares Nacionais: ensino médio. /ME/SEM. Brasília: Ministério da Educação, 1999.

CUNHA, M. I. et al. As políticas públicas e docência na universidade. In: CUNHA, M. I. (org.). Formatos avaliativos e concep̧̧ão de docência. Campinas: Autores Associados, 2005. p. 69-91.

DAVID, C. et al. Padrões e Competência em TIC para Professores: Marco Político. Paris: Título original: ICT competency standards for teachers: policy framework. UNESCO, 2008. (Título original: ICT competency standards for teachers: policy framework). Disponível em: http://unesdoc.unesco.org/images/0015/001562/156209por.pdf. Acesso em: 10 jan. 2020.

DEMO, P. Habilidades do Século XXI . Boletim Técnico do SENAC, Rio de Janeiro, v. 34, n. 2, maio/ago. 2008. Disponível em: http://www.senac.br/BTS/342/artigo-1.pdf. Acesso em: 15 jan. 2020.

EDUCAUSE Horizon Report 2019. Higher Education Edition. Disponível em: https://library.educause.edu/-/media/files/library/2019/4/2019horizonreport.pdf?la=en\& hash=C8E8D444AF372E705FA1BF9D4FF0DD4CC6F0FDD1. Acesso em: 19 jan. 2020.

ELLIOTT', J. La investigación-acción en educación. Madrid: Ediciones Morata, 1997.

GEORGEN, P. Universidade e compromisso social. In: RISTOFF, D; SAVEGNANI, P. Universidade e compromisso social. Brasília: Instituto Nacional de Estudos e Pesquisas Educacionais Anísio Teixeira, 2006.

KAFAI, Y. et al. National Research Council. Being Fluent with Information Technology. National Academy Press. Washington, D.C.: National Academy Press, 1999. Disponível em: http://www.nap.edu/catalog/6482.html. Acesso em: 19 jan. 2020.

KEMMIS, S.; McTAGGART, R. Como planificar la investigación-acción. Barcelona: Laertes, 1988.

MALLMANN, E. M. SCHNEIDER, D. R; MAZZARDO, M. D. Fluência TecnológicoPedagógica (FTP) dos Tutores. CINTED-UFRGS - Novas Tecnologias na Educação, v. 11, n. 3, dez. 2013. Disponível em: https://seer.ufrgs.br/renote/article/view/44468. Acesso em: 10 jan. 2020.

MALLMANN; E. M.; JACQUES, J. S. Design pedagógico de recursos educacionais abertos em ambiente virtual. Linguagens, Educação e Sociedade. Revista do Programa de PósGraduação em Educação da UFPI, Teresina, Ano 22, n. 37, jul./dez. 2017. Disponível em: https://ojs.ufpi.br/index.php/lingedusoc/article/view/7581/pdf. Acesso em: 18 jan. 2020.

PAPERT, S.; RESNICK, M. Technological Fluency and the Representation of Knowledge. Proposal to the National Science Foundation. Massachusetts: MIT Media Lab, 1995. Disponível em: http://grantome.com/grant/NSF/DRL-9553474. Acesso em: 19 jan. 2020. 
SCHLEMMER, E. Políticas e práticas na formaşão de professores a distância: por uma emancipação digital cidadã. (2011). Disponível em: http://goo.gl/BcRxWQ. Acesso em: 19 jan. 2020.

SCHLEMMER, E.; BACKES, L. Metaversos: novos espaços para construção do conhecimento. Revista Diálogo Educacional, Curitiba, v. 8, n. 24, maio/ago. 2008. Disponível em: https://www.redalyc.org/pdf/1891/189116834014.pdf. Acesso em: 02 abr. 2017.

SCHRAIBER, R. T.; MALLMANN, E. M. Performance pedagógica educação a distância: estado da arte, relações e conceito. Boletim Técnico do Senac, Rio de Janeiro, v. 44, n. 2, maio/ago. 2018. Disponível em: http://www.bts.senac.br/index.php/bts/article/view/697. Acesso em: 19 jan. 2020.

SHIMABUKURO, J. SPOCs Are MOOC Game Changers. In: Educational Technology and Change Journal. 2013. Disponível em: https://etcjournal.com/2013/09/26/spocs-are-moocgame-changers/. Acesso em: 20 fev. 2020.

SOARES, S. R.; CUNHA, M. I. Programas de pós-graduação em educação: lugar de formação da docência universitária? Revista Brasileira de Pós-Graduação, Brasília, v.7, n. 14, dez. 2010, p. 577-604.

TAKAHASHI, T. (org) (2000). Sociedade da informação no Brasil - Livro Verde.

TAROUCO, L. M. R. Um panorama da fluência digital na sociedade da informação. In: BEHAR, P. A. (Org.). Competências em Educação a Distância. Porto Alegre: Penso, 2013.

TOEBE, I. C. D. et al. Fluência Tecnológico-Pedagógica na Formação Inicial de Professores Mediada por Tecnologias Educacionais em Rede. VII Congresso Brasileiro de Informática na Educação, 2018, Fortaleza. In: Anais ... Fortaleza, 2018. p. 1138-1146.

UNESCO. Declaração REA de Paris. 2012. Disponível em: http://www.unesco.org/new/fileadmin/MULTIMEDIA/HQ/CI/CI/pdf/Events/Portu guese_Paris_OER_Declaration.pdf. Acesso em: 20 fev. 2020.

VEIGA, I. P. Alencastro. Docência universitária na educação superior. 2006. Disponível em: https://www.unochapeco.edu.br/static/data/portal/downloads/2130.pdf. Acesso em: 29 jan. 2020.

WILSON, C. et al. Alfabetização Midiática e Informacional: curriculo para formação de professores. Brasilia: UNESCO, UFTM, 2013. 194 p. Disponível em: http://unesdoc.unesco.org/images/0022/002204/220418por.pdf. Acesso em: 15 fev. 2020.

RECEBIDO: $29 / 02 / 2020$

APROVADO: $24 / 07 / 2020$

RECEIVED: 02/29/2020

APPROVED: 07/24/2020

RECIBIDO: $29 / 02 / 2020$

APROBADO: $24 / 07 / 2020$ 